\title{
Predictors of outcome events and 6-year mortality after carotid endarterectomy and carotid stenting in patients with carotid artery stenosis
}

\author{
Norbert Leško ${ }^{1}$, Milan Maretta $^{1}$, Matej Škorvánek ${ }^{1}$, Mária Frankovičová $^{2}, V^{\prime a d i m i ́ r ~ S i h o t s k y ́}{ }^{2}$, \\ L'ubomír Špak ${ }^{3}$, Zuzana Gdovinová ${ }^{1}$ \\ ${ }^{1}$ Department of Neurology, P. J. Safarik University, Kosice, Slovakia \\ ${ }^{2}$ Clinic of Vascular Surgery, Eastern Slovak Cardiovascular Institute and P. J. Safarik University, Kosice, Slovakia \\ ${ }^{3}$ Department of Angiology, Eastern Slovak Cardiovascular Institute and P. J. Safarik University, Kosice, Slovakia
}

\begin{abstract}
Aim. The aim of our study was to evaluate the results of CEA and CAS in patients with carotid artery stenosis, and their effect on long-term mortality and morbidity, as well as to identify predictors of long-term mortality in a single-centre observational study.

Clinical rationale. While data on short-term morbidity and mortality after carotid endarterectomy (CEA) and carotid stenting (CAS) is robust, there is only a limited amount of literature on long-term mortality and its predictors five years-plus post these procedures.
\end{abstract}

Material and methods. Consecutive patients with symptomatic and asymptomatic internal carotid artery stenosis treated with CEA or CAS in a single centre in eastern Slovakia between 2012 and 2014 were included. We recorded basic sociodemographic data, the presence of co-morbidities and periprocedural complications. Clinical and sonographic follow-up was performed three and 12 months after the procedures. Patient survival data and any stroke data was obtained at the end of a six-year follow-up.

Results. We included 259 patients after CEA (mean age $67.4 \pm 8.5,64.5 \%$ men) and 321 after CAS (mean age 66.9 $\pm 8.4,73.5 \%$ men). We did not identify a statistically significant difference in short-term or long-term mortality, survival times, or the presence of short-term or long-term complications between the CEA and CAS groups. Predictors of long-term mortality included age and diabetes mellitus in both cohorts. Repeated interventions were related to increased mortality only in the CAS cohort.

Conclusions. The results of our study show that long-term mortality does not differ between CEA and CAS.

Key words: carotid stenting, carotid endarterectomy, mortality, predictors

(Neurol Neurochir Pol 2021; 55 (1): 67-73)

\section{Introduction}

Stroke is the second most common cause of death and a leading cause of disability worldwide. Carotid stenosis is responsible for approximately $20 \%$ of all ischaemic strokes [1]. There is an accepted consensus on indications for the treatment of symptomatic carotid stenosis in secondary stroke prevention [2], but agreement on the treatment of asymptomatic stenosis is less consistent. Historically, there have been discussions about which revascularisation method should be the first choice, and how this choice affects long-term outcomes in patients after stroke. In this regard, data on long-term mortality and its predictors is somewhat limited.

Therefore, the aim of our study was to evaluate the results of carotid endarterectomy (CEA) and carotid stenting (CAS) and their effect on long-term mortality, and to identify predictors of long-term mortality in the revascularisation centre for our referral area. 


\section{Materials and methods}

\section{Design}

This was a single-centre observational longitudinal follow-up study.

\section{Patients}

All patients with symptomatic and asymptomatic stenosis of the carotid artery from eastern Slovakia who underwent extracranial carotid revascularisation (carotid endarterectomy at the Dept. of Vascular Surgery and carotid angioplasty stenting at the Dept. of Angiology, VUSCH Košice, Slovakia) between 2012 and 2014 were included in the study. A total of 580 patients, 259 after carotid endarterectomy and 321 after carotid stenting, were included. No patient was excluded from the study by investigators. The choice of revascularisation treatment (CEA or CAS) was agreed by the treating vascular surgeon and the angiologist according to current guidelines and periprocedural risk evaluation, although the patient's preference was also taken into account. Our study was performed according to the Declaration of Helsinki 1975; it was approved by the local ethics committee and all patients signed written informed consent prior to enrollment.

\section{Data collection and procedures}

Carotid stenosis was evaluated as symptomatic if patients had experienced ischaemic stroke or transient ischaemic attack (TIA) within the last six months.

Carotid endarterectomy (CEA) was performed under general anaesthesia. A shunt was used selectively when brain oxygen saturation measured by perioperative transcranial monitoring was decreased by $20 \%$ of its normal value. Eversion or the classical method was used. Patients scheduled for CEA received a single antiplatelet medication which was not discontinued for the surgery.

Carotid stenting (CAS) was carried out following a standardised protocol; the percutaneous transfemoral approach under local anaesthesia was used. The most commonly used devices were XACT (Abbott), Protege (Medtronic), Cristallo Ideale (Invatec) and Sinus-Carotid (Optimed). All procedures were performed with cerebral protection devices, distal protection (filters), or a proximal protection device (Mo.Ma). Patients scheduled for CAS received antiplatelet therapy consisting of acetylsalicylic acid (mean dosage $100 \mathrm{mg} /$ day) and clopidogrel (75 mg/day) for at least three days before and three months after CAS. Low-Molecular-Weight Heparin (LMWH) 3000-5000 IU i.a. was given routinely after femoral artery puncture at the beginning of the procedure, and intravenous Atropin $0.5-1.5 \mathrm{mg}$ was used to prevent bradycardia.

Patients underwent a standard neurological examination after the revascularisation procedure, as well as three and 12 months after the procedure. When a worsening of neurological findings was determined, a neuroimaging procedure (brain CT/MRI) was performed without delay.
Duplex ultrasound examination of extracranial carotid arteries was carried out three and 12 months after the procedure (Philips HD11XE, Philips Ultrasound, Bothell, WA, USA with linear 3-12MHz probe).

\section{Outcome measures}

Stroke was defined as any new episode of neurological dysfunction caused by focal cerebral, spinal, or retinal infarction and classified as fatal, disabling (modified Rankin Score $\geq 3$ ), or nondisabling (modified Rankin Score $<3$ ). In addition, the presence of transient ischaemic attack defined as a new brief episode of neurological dysfunction caused by focal brain or retinal ischaemia, with clinical symptoms typically lasting less than one hour, and without evidence of acute infarction, were recorded.

The primary outcome was the combined risk of any stroke, or death within 30 days. Secondary outcomes were any stroke, disabling stroke, TIA, myocardial infarction, severe local complications (after CAS) and non-severe complications (nerve palsy after CEA, hypotension and bradycardia after CAS). Late outcomes included the combined endpoint of ipsilateral stroke, restenosis (evaluated by ultrasound examination) after three and 12 months, 6-year mortality rate, and the occurrence of any stroke during those six years. Patient survival data at the end of the 6-year follow-up was obtained from the National Health Care Surveillance Authority for all included subjects. Data on the presence of any stroke during the follow up period was obtained from the National Centre of Health Information also for all included subjects, including date and type of event.

\section{Statistical analyses}

Statistical analyses were performed using statistical software SPSS version 25.0 for Windows (SPSS Inc., Chicago, IL, USA). Firstly, we described the basic characteristics of subjects after CEA and CAS; differences between the groups were evaluated using the Chi-squared test and two-tailed t-test. Subsequently, characteristics of subjects who were alive or deceased by the end of follow-up for both groups after CEA or CAS were described, and differences were evaluated using the Chi-squared test and two-tailed t-test. Consequentially, variables that were significantly different between the alive or deceased groups were entered into a multinomial logistic regression separately for patients after CEA and CAS. Finally, Kaplan-Meier analyses, including Mantel-Cox log-rank test, were used to estimate the long-term survival for both groups and intervals free of stroke after the procedure in both groups.

\section{Results}

Our sample consisted of 259 patients after CEA, with a mean age of $67.4 \pm 8.5$ ( $64.5 \%$ men), and 321 patients after CAS, with a mean age of $66.9 \pm 8.4(73.5 \%$ men). Male gender was more common in the CAS group; however, this was only in the group of asymptomatic patients. Patients after CAS had more frequent 
Table 1. Characteristics of study population based on type of intervention

\begin{tabular}{|c|c|c|c|}
\hline & CEA & CAS & Statistical significance \\
\hline No. of patients & 259 & 321 & $p=n s$ \\
\hline Age & $67.4 \pm 8.5$ & $66.9 \pm 8.4$ & $p=n s$ \\
\hline $\operatorname{Sex}(M / F)$ & $167 / 92$ & $236 / 92$ & $p=0.023$ \\
\hline Past smoking & $128(49.4 \%)$ & $180(56.1 \%)$ & $p=n s$ \\
\hline Current smoking & $48(18.5 \%)$ & 71 (22.1\%) & $p=n s$ \\
\hline Atrial fibrillation & $36(13.9 \%)$ & $37(11.5 \%)$ & $p=n s$ \\
\hline Diabetes mellitus & $105(40.5 \%)$ & $125(38.9 \%)$ & $p=n s$ \\
\hline Arterial hypertension & $243(93.8 \%)$ & $294(91.8 \%)$ & $p=n s$ \\
\hline Hyperlipidaemia & $153(59.1 \%)$ & $168(61.7 \%)$ & $\mathrm{p}=\mathrm{ns}$ \\
\hline Hypercoagulation state & $8(3.1 \%)$ & $23(7.2 \%)$ & $p=0.04$ \\
\hline $\mathrm{CHD}$ or $\mathrm{Ml}$ & $164(63.3 \%)$ & $205(63.9 \%)$ & $p=n s$ \\
\hline PAD & $54(20.8 \%)$ & $82(25.5 \%)$ & $p=n s$ \\
\hline Past stroke or TIA & $166(64.1 \%)$ & $211(65.7 \%)$ & $p=n s$ \\
\hline Symptomatic stenosis & $102(39.4 \%)$ & $112(34.9 \%)$ & $p=n s$ \\
\hline Stenosis $>70 \%$ & $233(90.0 \%)$ & 304 (94.7\%) & $p=0.038$ \\
\hline left/right & $129(50 \%)$ & $164(51.4 \%)$ & $\mathrm{p}=\mathrm{ns}$ \\
\hline Severe complications within 30 days & $15(5.8 \%)$ & $13(4.0 \%)$ & $p=n s$ \\
\hline Non-severe complications within 30 days & $92(35.5 \%)$ & $59(18.4 \%)$ & $p<0.001$ \\
\hline Severe complications after 3 months* & $4 / 138(2.9 \%)$ & $10 / 181(5.5 \%)$ & $p=n s$ \\
\hline Non-severe complications after 3 months* & $16 / 138(11.6 \%)$ & $4 / 181(2.2 \%)$ & $p=0.002$ \\
\hline Severe complications within 12 months* & $4 / 74(5.4 \%)$ & $6 / 53(11.3 \%)$ & $p=0.001$ \\
\hline Verified restenosis - within 12 months* & $6 / 120(5.0 \%)$ & $11 / 160(6.9 \%)$ & $p=n s$ \\
\hline Contralateral $>70 \%$ stenosis or occlusion & $50(19.3 \%)$ & $89(27.7 \%)$ & $p=0.02$ \\
\hline No complication within 30 days & 234 & 305 & $p=n s$ \\
\hline \multicolumn{4}{|l|}{ Type of severe complication within 30 days } \\
\hline Mild stroke or TIA & $2(0.8 \%)$ & $7(2.2 \%)$ & \\
\hline Severe stroke & $10(3.9 \%)$ & $4(1.2 \%)$ & \\
\hline Haemorrhagic stroke & 0 & $2(0.6 \%)$ & \\
\hline Any stroke & $12(4.6 \%)$ & $13(4.0 \%)$ & \\
\hline MI & $3(1.2 \%)$ & $1(0.3 \%)$ & \\
\hline Severe local complications at site of CAS & 0 & $3(1.0 \%)$ & \\
\hline Death & 0 & 0 & \\
\hline Death by the end of follow-up & $83(32.0 \%)$ & $93(29.0 \%)$ & $\mathrm{p}=\mathrm{ns}$ \\
\hline Repeated intervention & $21(8.1 \%)$ & $37(11.5 \%)$ & $\mathrm{p}=\mathrm{ns}$ \\
\hline Presence of any stroke during 7-year follow up & & & $\mathrm{p}=\mathrm{ns}$ \\
\hline Ischaemic stroke & $33(12.7 \%)$ & $51(15.9 \%)$ & \\
\hline Subarachnoid haemorrhage & $3(1.2 \%)$ & $1(0.3 \%)$ & \\
\hline Intracerebral haemorrhage & 0 & $5(1.6 \%)$ & \\
\hline
\end{tabular}

CEA - carotid endarterectomy; CAS - carotid stenting; CHD - coronary heart disease; $\mathrm{MI}$ - myocardial infarction; PAD — peripheral artery disease; TIA - transient ischaemic attack; ${ }^{\circ}$ patients who were re-examined including ultrasound after three and 12 months of follow-up

hypercoagulation states, $>70 \%$ stenosis of the internal carotid artery (ICA), contralateral $>70 \%$ stenosis or occlusion of ICA, and severe complications after 12 months. Patients after CEA had more frequent non-severe complications immediately afterwards as well as three months after the procedure.
No differences regarding time period between qualifying event (stroke/TIA) and procedure (CEA vs. CAS) were observed $(17.6 \pm 25.6$ vs. $19.5 \pm 31.4$ days; $\mathrm{p}=0.62)$ in the group of symptomatic patients.

Detailed characteristics of the sample are set out in Table 1. 
Table 2. Clinical characteristics of patients surviving and deceased after CEA and CAS

\begin{tabular}{|c|c|c|c|c|c|c|}
\hline & \multicolumn{3}{|c|}{ CEA } & \multicolumn{3}{|c|}{ CAS } \\
\hline & Died & Survived & $\begin{array}{c}\text { Statistical } \\
\text { significance }\end{array}$ & Died & Survived & $\begin{array}{c}\text { Statistical } \\
\text { significance }\end{array}$ \\
\hline No. of patients & 83 & 176 & & 93 & 223 & \\
\hline Age & $69.7 \pm 7.8$ & $66.1 \pm 8.6$ & $p=0.002$ & $71.4 \pm 8.8$ & $65.5 \pm 7.8$ & $p<0.001$ \\
\hline $\operatorname{Sex}(M / F)$ & $60 / 23$ & $107 / 69$ & $\mathrm{p}=\mathrm{ns}$ & $72 / 21$ & $164 / 64$ & $p=n s$ \\
\hline Past smoking & $41(50 \%)$ & $87(49 \%)$ & $p=n s$ & $47(50 \%)$ & $133(58 \%)$ & $p=n s$ \\
\hline Current smoking & $16(19 \%)$ & $32(18 \%)$ & $p=n s$ & $9(10 \%)$ & $62(27 \%)$ & $p=0.001$ \\
\hline Atrial fibrillation & $12(14 \%)$ & $24(14 \%)$ & $p=n s$ & $21(23 \%)$ & $16(7 \%)$ & $p<0.001$ \\
\hline Diabetes mellitus & $43(58 \%)$ & $57(32 \%)$ & $p<0.001$ & $48(52 \%)$ & $77(34 \%)$ & $p=0.004$ \\
\hline Arterial hypertension & $78(94 \%)$ & $165(94 \%)$ & $p=n s$ & $86(92 \%)$ & $208(91 \%)$ & $\mathrm{p}=\mathrm{ns}$ \\
\hline Hyperlipidaemia & $48(58 \%)$ & $105(60 \%)$ & $p=n s$ & $53(57 \%)$ & $145(64 \%)$ & $p=n s$ \\
\hline Hypercoagulation state & 0 & $8(5 \%)$ & $p=n s$ & $6(6 \%)$ & $17(7 \%)$ & $p=n s$ \\
\hline $\mathrm{CHD}$ or $\mathrm{MI}$ & $63(76 \%)$ & $101(57 \%)$ & $p=0.004$ & 75 (81\%) & $130(57 \%)$ & $p<0.001$ \\
\hline PAD & $23(28 \%)$ & $31(17 \%)$ & $\mathrm{p}=\mathrm{ns}$ & $29(31 \%)$ & $53(23 \%)$ & $\mathrm{p}=\mathrm{ns}$ \\
\hline Past stroke or TIA & $55(66 \%)$ & $111(63 \%)$ & $\mathrm{p}=\mathrm{ns}$ & $67(72 \%)$ & $144(63 \%)$ & $\mathrm{p}=\mathrm{ns}$ \\
\hline Symptomatic stenosis & $38(46 \%)$ & $64(36 \%)$ & $\mathrm{p}=\mathrm{ns}$ & $39(42 \%)$ & $73(32 \%)$ & $p=n s$ \\
\hline Stenosis > 70\% & $71(86 \%)$ & $162(92 \%)$ & $\mathrm{p}=\mathrm{ns}$ & $87(94 \%)$ & $217(95 \%)$ & $\mathrm{p}=\mathrm{ns}$ \\
\hline Severe complications within 30 days & $9(11 \%)$ & $6(3 \%)$ & $p=0.023$ & $7(8 \%)$ & $6(3 \%)$ & $p=0.044$ \\
\hline Non-severe complications within 30 days & $27(33 \%)$ & $65(37 \%)$ & $\mathrm{p}=\mathrm{ns}$ & $16(17 \%)$ & $43(19 \%)$ & $p=n s$ \\
\hline Severe complications after 3 months & 0 & $4(4 \%)$ & $p=0.003$ & $5 / 50(10 \%)$ & $5 / 131(4 \%)$ & $\mathrm{p}=\mathrm{ns}$ \\
\hline Non-severe complications after 3 months & 0 & $16(16 \%)$ & $p=0.001$ & $2 / 50(4 \%)$ & $2 / 131(2 \%)$ & $\mathrm{p}=\mathrm{ns}$ \\
\hline Severe complications within 12 months & $1 / 12(8 \%)$ & $3 / 61(5 \%)$ & $p=0.006$ & $5 / 10(50 \%)$ & $1 / 43(2 \%)$ & $p<0.001$ \\
\hline Verified restenosis within 12 months & $1 / 26(4 \%)$ & $5 / 93(5 \%)$ & $p=0.009$ & $6 / 43(14 \%)$ & $5 / 112(5 \%)$ & $\mathrm{p}=\mathrm{ns}$ \\
\hline Contralateral $>70 \%$ stenosis or occlusion & $21(25 \%)$ & $29(16 \%)$ & $\mathrm{p}=\mathrm{ns}$ & $31(33 \%)$ & $58(25 \%)$ & $\mathrm{p}=\mathrm{ns}$ \\
\hline No complication within 30 days & 73 & 163 & $p=n s$ & 80 & 213 & $p=0.009$ \\
\hline Type of severe complication within 30 day & 1 & 1 & & 1 & 6 & \\
\hline Mild stroke or TIA & 6 & 4 & & 3 & 1 & \\
\hline Severe stroke & 0 & 0 & & 2 & 0 & \\
\hline Intracerebral haemorrhage & 2 & 1 & & 1 & 0 & \\
\hline MI & 0 & 0 & & 0 & 3 & \\
\hline Severe local insertion complications (CAS) & 0 & 0 & & 0 & 0 & \\
\hline \multicolumn{7}{|l|}{ Death } \\
\hline Repeated intervention & $8(10 \%)$ & $13(7 \%)$ & $p=n s$ & $17(18 \%)$ & $20(9 \%)$ & $p=0.016$ \\
\hline
\end{tabular}

Patients after CEA surviving at the end of follow-up had significantly younger age, less frequent diabetes mellitus (DM) coronary heart disease (CHD) or myocardial infarction (MI), less frequent severe complications immediately after the procedure, and more frequent severe and non-severe complications three months after the procedure.

Patients after CAS surviving at the end of follow-up had significantly younger age, less atrial fibrillation (AF), DM, $\mathrm{CHD}$ or MI, less frequent severe complications immediately after the procedure and repeated interventions. They were more commonly current smokers, and there was a significant difference among the types of complications within 30 days after the intervention. Detailed clinical characteristics of patients surviving and deceased after CEA and CAS are set out in Table 2.

In a multinomial logistic regression model controlled for all variables identified as statistically significant in Table 2, 6-year mortality in the group after CEA was significantly related to DM (OR=2.28, 95\% CI 1.27-4.08), older age (OR $=1.05,95 \% \mathrm{CI} 1.01-1.09)$ and severe complications within 12 months (OR $=2.76,95 \%$ CI 1.06-7.25). In the group of subjects after CAS, 6-year mortality was related to DM $(\mathrm{OR}=1.96,95 \% \mathrm{CI} 1.12-3.42)$, older age $(\mathrm{OR}=1.08,95 \% \mathrm{CI} 1.04$ -1.12), severe complications within 12 months $(\mathrm{OR}=3.40$, 95\% CI 1.22-9.52), and repeated interventions ( $\mathrm{OR}=3.22$, 95\% CI 1.34-7.69) (Tab. 3). 
Table 3. Multinomial logistic regression - predictors of 6-year mortality in patients after CEA/CAS

\begin{tabular}{|c|c|c|c|c|c|c|c|}
\hline & \multicolumn{3}{|c|}{ CEA } & & \multicolumn{3}{|c|}{ CAS } \\
\hline & OR & $95 \% \mathrm{Cl} 95$ & Significance & & OR & $95 \% \mathrm{Cl} 95$ & Significance \\
\hline Diabetes mellitus & 2.28 & $1.27-4.081$ & $p=0.006$ & Diabetes mellitus & 1.96 & $1.12-3.42$ & $p=0.018$ \\
\hline Age & 1.05 & $1.01-1.09$ & $p=0.018$ & Age & 1.08 & $1.04-1.12$ & $p<0.001$ \\
\hline $\begin{array}{l}\text { Severe complications within } \\
12 \text { months }\end{array}$ & 2.76 & $1.06-7.25$ & $p=0.038$ & $\begin{array}{l}\text { Severe complications } \\
\text { within } 12 \text { months }\end{array}$ & 3.40 & $1.22-9.52$ & $p=0.019$ \\
\hline & & & & Repeated intervention & 3.22 & $1.34-7.69$ & $p=0.009$ \\
\hline
\end{tabular}

In Kaplan-Meier analysis, the mean survival time in the CEA group during our follow up was $73.0 \pm 2.0$ months $(95 \%$ CI 69.1-76.8). For the CAS group, it was $79.5 \pm 1.8$ months (95\% CI 76.0-83.0). The Mantel-Cox log-rank test did not identify a statistically significant difference between survival of the CEA and CAS patient groups (Fig. 1A). The mean survival time free of stroke in the CEA group during our follow up was $78.3 \pm 1.6$ months (95\% CI 75.2-81.4). For the CAS group, it was $79.4 \pm 1.7$ months (95\% CI 76.1-82.7). While the long-term prevalence of stroke was more common in the CAS group, the Mantel-Cox log-rank test did not identify a statistically significant difference between intervals free of stroke in the CEA and CAS patient groups (Fig. 1B).

\section{Discussion}

Our results show that long-term mortality, as well as the long-term prevalence of stroke, does not differ between patients undergoing CEA and those undergoing CAS.

Several previous studies and meta-analyses have reported increased short-term recurrence of any stroke or death within 30 days or three months after CAS compared to CEA [3-6].

This was, however, not replicated in our study. We found no significant differences between CAS and CEA in any type of stroke (13 and 12, respectively, $\mathrm{p}=\mathrm{ns}$ ) or death ( 0 in both groups) after 30 days, or the prevalence of any severe complications after three months. Similar findings were reported from the SPACE study, which did not show higher rates of ipsilateral stroke or death within 30 days after CAS or CEA (6.92\% and 6.45\%, respectively, RR 1.07 ITT) [7].

On the other hand, our finding that long-term mortality does not significantly differ after CEA or CAS is in line with most previous studies. After three years of follow-up, the CAVATAS study reported no difference in mortality or disabling stroke between CAS and CEA (14.3\% vs. $14.2 \%$ HR 1.03) [8], and the SAPPHIRE study [9] verified no significant difference in the rate of death $(18.6 \%$ vs. $21.0 \%, \mathrm{p}=0.68)$ or major and minor stroke ( $9.0 \%$ vs. $9.0 \%, p=0.99)$ between CAS and CEA. Similar findings were shown in the CREST study [10], where the 4-year rate of stroke or death among symptomatic patients (CAS vs. CEA; $8.0 \%$ vs. $6.4 \%$; HR 1.37 , $\mathrm{p}=0.14$ ) did not statistically differ. In the EVA-3S study [3] the 4-year risks of stroke or death or non-procedural stroke were higher in CAS-treated patients ( $11.1 \%$ vs. $6.2 \%$, HR 1.97, $\mathrm{p}=0.03)$; however, this was mostly attributed to the higher periprocedural risk of CAS, as the risk of ipsilateral stroke beyond 30 days was low and similar in both groups.

The only study thus far conducted reporting a follow-up beyond 6 years is the extended CREST study, which did not report significant differences between any stroke or death after 10 years; however, the authors did not provide a value for 10-year mortality alone [11].

While the results of long-term mortality are fairly consistent across studies, predictors of mortality are less homogeneous. In contrast to our study, where higher age was a predictor of mortality in both CEA- and CAS-treated patients, Brott et al. [11] found no correlations between risk factors (age, sex, stenosis type and status) and the rate of death or stroke. Similarly, Brott et al. [12] did not find any modifying effect of $\mathrm{DM}$, hypertension, hyperlipidemia or cardiovascular diseases on long-term prevalence of stroke or death. These results are again in contrast to ours, as diabetes mellitus was a predictor of 6-year mortality in both CEA- and CAS-treated patients. Nevertheless, it is important to note that Brott et al. [2019] [12] did not differentiate between stroke and death in their analyses, and thus the effect of these predictors on mortality alone cannot be compared directly. Also, in another study, Parlani et al. [13] found no relationship between stroke or death and the presence of DM; however, their findings in a CEA-treated group show a significantly increased risk of stroke or death when using insulin (6.5\% vs. $1.7 \%$; OR 3.93; $\mathrm{p}=0.017)$.

We did not observe any significant differences in the rate of severe re-stenosis or occlusions between CEA and CAS after 12 months. However, patients after CAS needed more repeated interventions, which at the end were an independent predictor of long-term mortality in the CAS cohort. In contrast to our results, several other studies $[7,14]$ have linked CAS to a higher rate of moderate as well as severe stenosis (13\% vs. $5 \%$, $\mathrm{p}=0.02 ; 10.7 \%$ vs. $4.6 \%, \mathrm{p}=0.009$; respectively).

Our study included all consecutive patients, respecting the standard inclusion criteria for both symptomatic and asymptomatic stenosis [15], and all procedures were performed by the same team of surgeons and angiologists meeting the SAPPHIRE and CREST trial proficiency requirements, thereby reducing the heterogeneity of procedural outcomes. Nevertheless, some limitations need to be considered. In particular, 


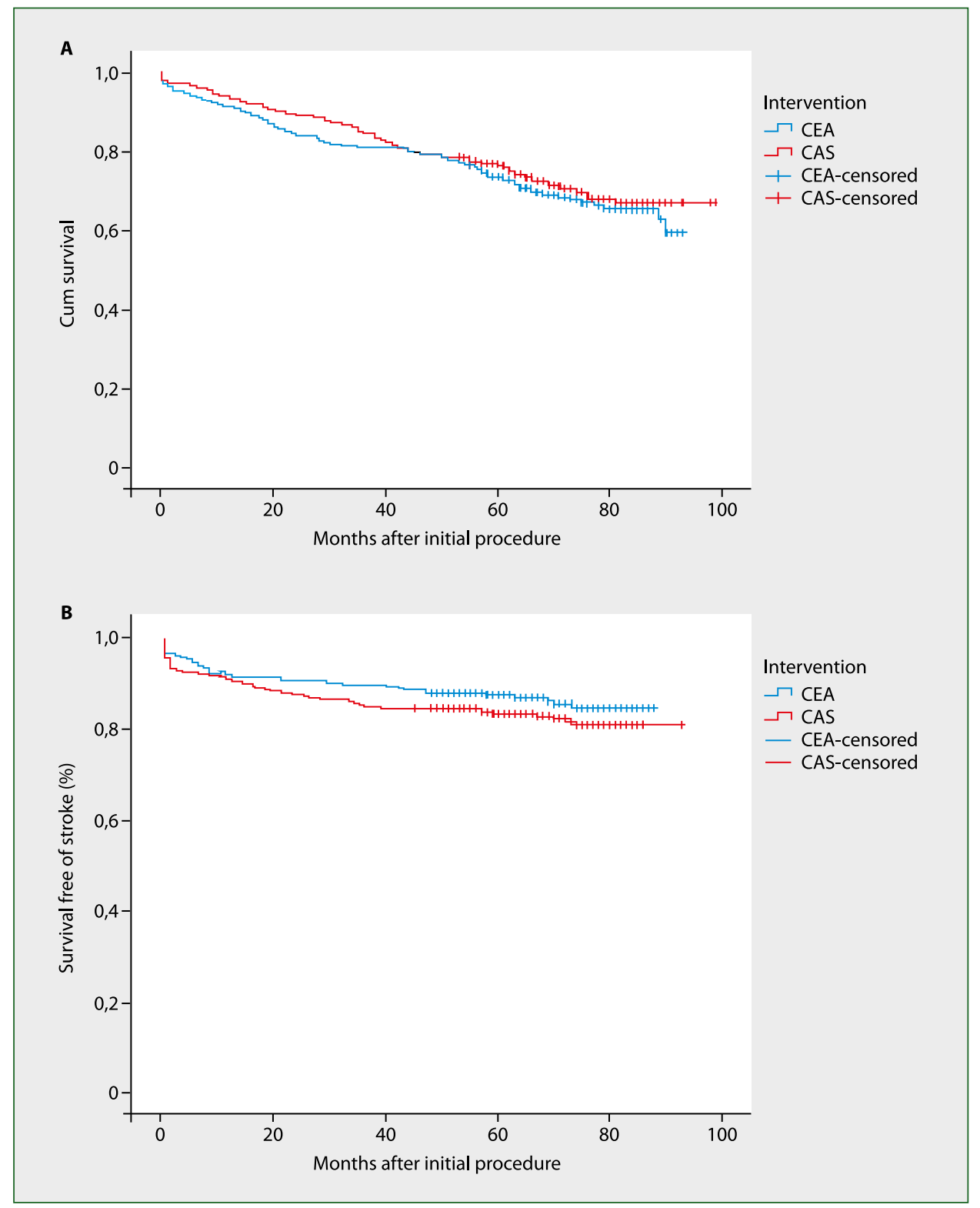

Figure 1. Results of Kaplan-Meier analysis in 259 patients after CEA and 321 patients after CAS in terms of A. Long-term survival of subjects after CEA and CAS, log-rank (Mantel-Cox) test chi-square 0.595, $p=0.441$; B. Survival free of stroke after initial intervention, log-rank (Mantel-Cox) test chi square 1.457, $p=0.227$

more detailed patient history regarding recurrent stroke and other comorbidities beyond 12 months follow-up, as well as cause of death, were not available. Also, patients were not assigned to the treatment groups randomly, and thus some selection bias may have been implicated in treatment assignment.

Our results show that long-term mortality, as well as the long-term prevalence of stroke, does not differ between patients undergoing CEA and CAS. Further research is necessary to better define predictors of mortality, which would be helpful in selecting the most appropriate procedure for our patients.
Acknowledgements: We acknowledge help from the Department of Vascular Surgery and Angiology of the Eastern Slovak Cardiovascular Institute and the National Centre of Health Information.

Ethical permission: This study was performed in accordance with the Declaration of Helsinki 1975; it was approved by the local ethics committee, and all patients signed written informed consent prior to enrollment.

Conflicts of interest: The authors have no conflict of interest to declare.

Funding sources: Supported by grant VEGA - 1/0380/19. 


\section{References}

1. 1.Grau AJ, Weimar C, Buggle F, et al. Risk factors, outcome, and treatment in subtypes of ischemic stroke: the German stroke data bank. Stroke. 2001; 32(11): 2559-2566, doi: 10.1161/hs1101.098524, indexed in Pubmed: 11692017.

2. Aboyans V, Ricco JB, Bartelink MLEL, et al. ESC Scientific Document Group. 2017 ESC Guidelines on the Diagnosis and Treatment of Peripheral Arterial Diseases, in collaboration with the European Society for Vascular Surgery (ESVS): Document covering atherosclerotic disease of extracranial carotid and vertebral, mesenteric, renal, upper and lower extremity arteriesEndorsed by: the European Stroke Organization (ESO)The Task Force for the Diagnosis and Treatment of Peripheral Arterial Diseases of the European Society of Cardiology (ESC) and of the European Society for Vascular Surgery (ESVS). Eur Heart J. 2018; 39(9): 763-816, doi: 10.1093/eurheartj/ehx095, indexed in Pubmed: 28886620.

3. Mas JL, Trinquart L, Leys D, et al. Endarterectomy Versus Angioplasty in Patients with Symptomatic Severe Carotid Stenosis (EVA-3S) trial: results up to 4 years from a randomised, multicentre trial. The Lancet Neurology. 2008; 7(10): 885-892, doi: 10.1016/s14744422(08)70195-9.

4. Carotid artery stenting compared with endarterectomy in patients with symptomatic carotid stenosis (International Carotid Stenting Study): an interim analysis of a randomised controlled trial. The Lancet. 2010; 375(9719): 985-997, doi: 10.1016/s0140-6736(10)60239-5.

5. Economopoulos KP, Sergentanis TN, Tsivgoulis G, et al. Carotid artery stenting versus carotid endarterectomy: a comprehensive meta-analysis of short-term and long-term outcomes. Stroke. 2011; 42(3): 687-692, doi: 10.1161/STROKEAHA.110.606079, indexed in Pubmed: 21233476.

6. Meier P, Knapp G, Tamhane U, et al. Short term and intermediate term comparison of endarterectomy versus stenting for carotid artery stenosis: systematic review and meta-analysis of randomised controlled clinical trials. BMJ. 2010; 340: c467, doi: 10.1136/bmj.c467, indexed in Pubmed: 20154049.

7. Eckstein HH, Ringleb P, Allenberg JR, et al. Results of the Stent-Protected Angioplasty versus Carotid Endarterectomy (SPACE) study to treat symptomatic stenoses at 2 years: a multinational, prospective, randomised trial. Lancet Neurol. 2008; 7(10): 893-902, doi: 10.1016/ S1474-4422(08)70196-0, indexed in Pubmed: 18774746.

8. Brown MM, Rogers J, Bland JM. Endovascular versus surgical treatment in patients with carotid stenosis in the Carotid and Vertebral Artery Transluminal Angioplasty Study (CAVATAS): a randomised trial. The Lancet. 2001; 357 (9270): 1729-1737. https://doi org/10 1016/ S1474. 4422; 09: 70228-5, doi: 10.1016/S1474-4422(09)70228-5.

9. Gurm HS, Yadav JS, Fayad P, et al. SAPPHIRE Investigators. Long-term results of carotid stenting versus endarterectomy in high-risk patients. N Engl J Med. 2008; 358(15): 1572-1579, doi: 10.1056/ NEJMoa0708028, indexed in Pubmed: 18403765.

10. Brott TG, Hobson RW, Howard G, et al. CREST Investigators. Stenting versus endarterectomy for treatment of carotid-artery stenosis. $\mathrm{N}$ Engl J Med. 2010; 363(1): 11-23, doi: 10.1056/NEJMoa0912321, indexed in Pubmed: 20505173.

11. Brott TG, Howard G, Roubin GS, et al. CREST Investigators. Long-Term Results of Stenting versus Endarterectomy for Carotid-Artery Stenosis. N Engl J Med. 2016; 374(11): 1021-1031, doi: 10.1056/ NEJMoa1505215, indexed in Pubmed: 26890472.

12. Brott TG, Calvet D, Howard G, et al. Long-term outcomes of stenting and endarterectomy for symptomatic carotid stenosis: a preplanned pooled analysis of individual patient data. Lancet Neurol. 2019; 18 (4): 348-356. https://doi org/10 1016/S1474. 4422; 19: 30028-6, doi: 10.1016/S1474-4422(19)30028-6.

13. Parlani G, De Rango P, Cieri E, et al. Diabetes is not a predictor of outcome for carotid revascularization with stenting as it may be for carotid endarterectomy. J Vasc Surg. 2012; 55(1): 79-89; discussion 88, doi: 10.1016/j.jvs.2011.07.080, indexed in Pubmed: 22056251.

14. Arquizan C, Trinquart L, Touboul PJ, et al. EVA-3S Investigators. Restenosis is more frequent after carotid stenting than after endarterectomy: the EVA-3S study. Stroke. 2011; 42(4): 1015-1020, doi: 10.1161/STROKEAHA.110.589309, indexed in Pubmed: 21311065.

15. Brott TG, Halperin JL, Abbara S, et al. ASA/ACCF/AHA/AANN/AANS/ ACR/ASNR/CNS/SAIP/ SCAI/SIR/SNIS/SVM/SVS guideline on themanagement of patients with extracranial carotid and vertebral artery disease: executive summary. Vasc Med. 2011; 124(4): 489-532, doi: 10.1161/STR.0b013e3182112cc2. 